\title{
Ensino de História: passados vivos e educação em questões sensíveis
}

Teaching History: Living Pasts and Education on Sensitive Issues

Nilton Mullet Pereira*

Fernando Seffner ${ }^{* *}$

\section{RESUMO}

Este artigo aborda temas socialmente controversos e sensíveis no âmbito do ensino de história. As questões socialmente vivas se constituem na contemporaneidade em objetos privilegiados dos currículos de história, em função, por um lado, das demandas sociais de grupos identitários e, de outro, dos movimentos que buscam interferir na liberdade de ensinar e no direito de aprender, direitos assegurados na Constituição Federal de 1988. O artigo quer construir a categoria de passado vivo como elemento central na constituição de currículos de ensino de história e, para isso, vale-se de um duplo movimento: a produtividade dos conceitos de residualidade e remanescência, e a decidida conexão da prática docente em história com o campo da educação em direitos humanos. Ao final, discutem-se algumas cenas escolares onde tais questões foram enfrentadas. Palavras-chave: residualidade; remanescência; educação em temas sensíveis.

\section{ABSTRACT}

This article discusses socially controversial subjects and sensitive themes in the context of History teaching. Socially keen questions are built nowadays on History curricula's privileged objects, according to social demands of identity groups, such as minorities, and movements that seek to restrict the freedom to teach and the right to learn, which are guaranteed by the Brazilian Federal Constitution of 1988. This study aims to analyze the category of living past as a central element in History teaching curricula establishment, thus, we made a double movement: productivity of residuality and remnant concepts, and the connection of History teaching with the field of education about human rights. We conclude by discussing some school situations that faced these issues.

Keywords: residuality; remaining forms; sensitive education.

\footnotetext{
* Universidade Federal do Rio Grande do Sul (UFRGS), Faculdade de Educação, Departamento de Ensino e Currículo. Porto Alegre, RS, Brasil.niltonmp.pead@gmail.com

** Universidade Federal do Rio Grande do Sul (UFRGS), Faculdade de Educação, Programa de Pós-Graduação em Educação. Porto Alegre, RS, Brasil. fernandoseffner@gmail.com
} 


\section{DAS ESTRATÉgIAS DE PRODUTIVIDAdE DO ENSINO DE HiSTÓRIA}

Um dos modos de saber da produtividade do ensino de história é estabelecer conexões com outros campos de pesquisa e ensino e com estratégias diversas de aprendizagem. Com isso conhecemos melhor as características do próprio campo analisado, bem como nos desafiamos a perceber sua produtividade diante das questões contemporâneas, das diferentes tradições teóricas, dos novos desafios das políticas públicas de formação docente, das marcas próprias das culturas juvenis e das novidades da historiografia. É o que temos feito em uma já longa trajetória de ocupação com o ensino de história.

Um esforço frutífero e antigo foi pensar a docência de história na conexão com as tarefas da leitura e da escrita na escola, como se pode ver em Seffner e Pereira (2008) e em Seffner (1998). A formação de professores(as) de história também tem sido alvo de nossas investigações. Analisamos a potencialidade do ensino de história em uma bem-sucedida política pública de formação docente inicial - o Pibid - em Seffner et al. (2016), e apresentamos e refletimos sobre as atividades realizadas no âmbito do projeto em Meinerz et al. (2013).

Pensando a formação docente continuada, novamente nos indagamos sobre as possibilidades da docência em história nos mestrados profissionais, em Gil et al. (2017). Investimento de fôlego tem sido feito para conhecer as possibilidades do uso de jogos para lecionar história, como se pode ver em Giacomoni e Pereira (2013). A problematização de temas canônicos no ensino de história na ótica das representações culturais contemporâneas foi objeto de Pereira (2017a), ao pensar as apropriações do medievo nos dias atuais. Problematizar as consequências, para as práticas docentes de história, dos numerosos documentos oficiais regulatórios que nos últimos anos têm sido produzidos pelo Governo Federal foi propósito da análise em Pereira e Rodrigues (2017), tomando como objeto a Base Nacional Comum Curricular.

A abordagem de temas socialmente controversos e sensíveis no âmbito do ensino de história já ocupou nossa atenção em produções como as de Pereira e Gitz (2013), com o tema do Holocausto na sala de aula; Gil e Seffner (2016), com a questão do diálogo da prática docente em história com as marcas das culturas juvenis no ensino médio; Seffner e Picchetti (2016), ao abordar as questões de gênero e sexualidade - objeto de acentuado pânico moral nos dias atuais quando de sua abordagem em sala de aula; Seffner (2016), ao abordar a 
escola como espaço público e o professor como um adulto de referência, não necessariamente em sintonia com as demandas oriundas das famílias e das religiões; Seffner (2017a), ao lidar com o delicado tema da liberdade de ensinar e do direito de aprender nas aulas de história; e em Seffner (2017b), ao analisar as demandas e organização cotidiana dos alunos e alunas que ocuparam as escolas públicas do Rio Grande do Sul no ano de 2016. Ainda nesse diapasão dos temas sensíveis e questões controversas, pensar o ensino de história em uma conjuntura de resistência foi objeto de análise em Pereira (2017b), trazendo à luz possibilidades e oportunidades para a prática docente de história diante do ambiente político atual.

As chamadas questões socialmente vivas se constituem em objetos privilegiados dos currículos de história, por um lado, em função das demandas sociais de grupos identitários e, por outro, pelos constantes ataques por que passam professores que se dedicam a dar atenção ao passado vivo. Em sintonia com a trajetória apresentada de modo resumido e com os desafios do tempo presente, este artigo pretende construir o conceito de passado vivo como elemento central na constituição de currículos de história na América Latina, na contemporaneidade. A ideia de passado vivo nos remete ao elemento da colonialidade que se revela uma continuidade na vida dos povos latino-americanos, em particular, dos brasileiros. Objetivamos trabalhar com o conceito de residualidades, no sentido de pensar um currículo de história voltado aos temas sensíveis e às questões socialmente vivas. A docência em geral e em história, em particular, estão sob a mira de grupos e movimentos que procuram questionar o caráter ético e político da educação e da formação do historiador. Nesse sentido, torna-se necessário uma reafirmação dos aspectos éticos e políticos das narrativas e das formas de expressão do conhecimento de que os professores se utilizam para criar e recriar conceitos históricos em sala de aula. Isso implica também abrir os currículos para os passados vivos e sensíveis, problematizando os marcadores tradicionais e eurocentrados de representar o tempo.

O objetivo deste artigo é se ocupar do modo como construímos narrativas e utilizamos formas de expressão dos passados sensíveis e vivos nas aulas de história, demonstrados mediante exemplos extraídos da prática cotidiana de orientadores de estágio docente em história. Trata-se de pensar a temporalidade histórica nas salas de aula, a partir dos conceitos de residualidade e 
remanscência, dando-lhe os contornos éticos e políticos que possam permitir pensar os passados vivos e sensíveis e colocá-los na forma de conteúdo da aula de História. Na esteira dessa discussão, pretendemos desenvolver o conceito de passado vivo, sob a inspiração da filosofia foucaultiana e da noção de passado prático de Hayden White, de maneira a propor que um encontro com um passado vivo consiste num movimento de aprendizagem ética que implica uma relação consigo mesmo.

O aspecto ético se refere, justamente, aos efeitos esperados do ensino, na medida em que o ato de ensinar faz um recorte no passado, e este se dá em função das demandas do presente (Jenkins, 2001). Os objetivos de docência estão implicados num processo de representação que tem efeitos no modo como as novas gerações olharão para si mesmas, para o seu mundo e para os outros. O caráter ético do ensino de história está justamente no processo de construção de si mesmo como sujeito de um olhar, como subjetividade marcada por se permitir realizar uma determinada interpretação do passado e, ao mesmo tempo, do seu lugar no presente. Estudar os passados sensíveis não significa apresentar ao aluno um conteúdo disciplinado e frio (White, 1995), mas colocá-lo diante de algo que desperta indignação frente à injustiça e a violação dos direitos humanos. A escrita da história sobre esses passados e seu ensino não são atitudes desinteressadas, mas voltadas ao futuro - um futuro de tolerância, de reconciliação com a justiça e com os direitos.

Cabe uma palavra, aqui, sobre a preocupação deste artigo e do ensino de história com o campo da educação em direitos humanos. A aproximação que desejamos entre a educação em história e em direitos humanos não é fortuita, pelo contrário, atende a um conjunto de dispositivos legais que, a partir da Constituição Federal de 1988, indicaram essa obrigatoriedade. Fruto mais visível para o campo escolar desse percurso das políticas públicas em direitos humanos foram dois atos do Executivo federal fazendo cumprir disposições da legislação: a promulgação do Plano Nacional de Educação em Direitos Humanos (Brasil, 2006) e das Diretrizes Nacionais da Educação em Direitos Humanos (Brasil, 2013). Mas há uma extensa legislação nos níveis estadual e municipal que indica essa obrigatoriedade. Em particular, os estados constituíram Comitês Estaduais de Educação em Direitos Humanos (CEEDH) a partir da instalação dos Conselhos Estaduais de Direitos Humanos. Essa estrutura alcança todas as unidades da Federação. ${ }^{1}$ Como resultado desse 
investimento, temos a produção e visibilidade de numerosas experiências pedagógicas, realizadas por professores e alunos com diferentes temas no guarda-chuva da educação em direitos humanos e em muitas e diferentes realidades e contextos culturais e educacionais do país. Parte da produção pode ser vista nas premiações anuais do Prêmio Nacional de Educação em Direitos Humanos e do Prêmio Ibero-americano de Educação em Direitos Humanos “Óscar Arnulfo Romero". Ao pensar o ensino de história como produtor de uma educação em temas sensíveis necessariamente alargamos o diálogo acerca dessa prática com a educação em direitos humanos.

Os direitos humanos têm seu documento legal internacional mais conhecido na Declaração Universal dos Direitos Humanos de 1948, aprovada no plenário das Nações Unidas, e que completa 70 anos em 2018 (ONU, 2009). Muitas décadas depois, a partir de iniciativas promovidas por vários países e por órgãos de cooperação bilateral e multilateral, as Nações Unidas lançaram o Programa Mundial para a Educação em Direitos Humanos e um Plano de Ação (ONU, 2006). O Brasil é signatário de todas essas iniciativas e, em sintonia com elas, desenvolveu políticas públicas e documentos oficiais próprios, tendo também integrado em seu ordenamento jurídico esses documentos internacionais com força de lei. Em cada país a educação em direitos humanos tomou cores próprias, a depender dos desafios culturais, políticos e sociais de cada contexto. Vale lembrar que aqui no Brasil a adesão a essa regulamentação internacional aconteceu quando o país avançava em termos de densidade democrática, tendo saído do período de ditadura militar e proclamado a chamada Constituição Cidadã em 1988, a Carta Magna que mais direitos sociais contém em toda a nossa história.

Desse modo, nossas diretrizes para a educação em direitos humanos no ambiente escolar se amparam tanto em princípios constitucionais quanto em metas desenhadas para alcance pela sociedade: a dignidade humana enquanto direito básico da vida assegurado a qualquer cidadão/ã brasileiro/a e definida como direito humano no texto constitucional de 1988; a igualdade de direitos pensada como terreno oportuno para a vida em sociedade e com justiça social e como dever de garantia pelo Estado e pelas políticas públicas; o reconhecimento e a valorização das diferenças e das diversidades, implicando um debate analítico de cada contexto e adoção de mecanismos jurídicos que tomem em conta os diferentes marcadores sociais da diferença que podem vir a produzir 
situações de desigualdade; a laicidade do Estado - princípio constitucional expresso na Constituição Federal de 1988 e que busca assegurar que o Estado não promoverá nenhuma religião em particular, mas zelará para que cada um possa professar o culto que mais lhe pareça adequado, em sintonia com as liberdades laicas (liberdade de consciência, liberdade de expressão e liberdade de crença, todas elas constando em nossa Carta Magna); a obrigatoriedade do exercício da gestão democrática nas políticas públicas de educação e que deve também estar expresso no cotidiano escolar e se encontra garantido tanto no texto constitucional quando nas ordenações do Plano Nacional de Educação e em legislações estaduais e municipais dali derivadas (Gomes, 2015); a transversalidade, a vivência e a globalidade, orientando a construção de ações pedagógicas da educação em direitos humanos que podem tanto se alocar em uma disciplina específica, como fazer parte de projetos colaborativos interdisciplinares; e a sustentabilidade socioambiental, percebida como garantia de futuro para a sociedade e para o planeta.

É sobre essa plataforma legal que avançamos neste artigo, com considerações em torno da produtividade do ensino de história quando busca dar conta da educação em temas sensíveis, e o faz orientado pelos princípios da educação em direitos humanos. Como historiadores, assumimos que não se pode falar de uma natureza humana anterior à história e à cultura, que se poderia localizar, identificar e definir por si mesma, para dali extrair direitos, deveres e contornos humanos que valeriam desde sempre e para sempre. Mas assumimos que, para o momento histórico-político-cultural em que vivemos, há um conjunto de princípios fundamentais ligados à dignidade humana e as melhores políticas para fazer viver e alargar as condições de vida com igualdade de oportunidades e direito à formação integral. A educação escolar - e a história como seu importante componente disciplinar - não pode estar alheia a esses propósitos. Vale lembrar que nos dias de hoje ainda temos no Brasil um longo caminho para assegurar uma vida em sociedade e no cotidiano escolar em que duas preocupações presentes em 1948, quando foi aprovada a Declaração Universal dos Direitos Humanos, possam ser consideradas como bem equacionadas: o direito ao mais amplo exercício da liberdade de expressão e de viver sem sentir medo, por parte de alunos e professores. O ensino de história tem parcela importante de responsabilidade e possibilidade de reverter esses dois traços culturais tão presentes no ordenamento social brasileiro. 
Feitas essas considerações de caráter mais geral e introdutório, encaminhamos agora nossa escrita para o terreno propriamente das práticas docentes em história, discutindo os conceitos de passado vivo, residualidade e remanescência, para chegar então a uma definição estratégica e pedagógica do que entendemos por educação em temas sensíveis. A partir disso vamos apresentar e analisar cenas do cotidiano de aulas de história em que se expressam tensões em torno do que nos propusemos a dialogar.

\section{SOBRE O PASSADO VIVO: RESIDUALIDADE E REMANESCÊNCIA}

Pensar um currículo de história para escola básica sem levar em consideração os temas desestruturantes e sensíveis é continuar a pensar um currículo eurocêntrico, cronológico, dominante, branco, heterossexual e racista. Dito de outro modo, consiste numa submissão da aula de História a um passado morto e objetificado. Situamos o debate neste artigo, ao contrário, em torno da ideia de passado vivo, que tem a ver com a insistência de um passado que não passa e que, desse modo, desestrutura a temporalidade progressiva e evolucionista da História eurocentrada.

Supor um passado vivo implica pensar duas urgências que se apresentam hoje ao ensino de história: as questões sensíveis e a diferença. As questões sensíveis nos deslocam e nos colocam no lugar de alguém que aborda o presente ao mesmo tempo que pensa o passado. São questões que nos levam a discutir o pertencimento e a necessidade que os jovens têm de se reconhecer numa história determinada, de olhar para si mesmos e se autoafirmarem. Ao mesmo tempo, entendemos pensar a diferença na forma da experiência. Quando estudamos um passado que não se relaciona com o nosso presente, de nenhum modo estamos estudando alguma coisa absolutamente apartada da vida de cada um de nós. Ao contrário, significa olhar para um passado distante do nosso presente, do ponto de vista da relação de pertencimento que temos com ele, e sentirmos um estranhamento, de tal forma que este nos permita abrirmo-nos a uma experiência alheia, nova, inusitada, que nos desloca do presente e nos leva ao futuro. Esse outro elemento que não é do pertencimento, mas sim do estranhamento, também é frutífero para o ensino de história e para a vida, porque nos leva a pensar o passado tendo um uso que permite problematizar o presente e imaginar experiências ainda imprevisíveis. 
O passado considerado diferença nos faz dar um salto do presente para pensar novos mundos possíveis.

Eis, portanto, duas urgências no ensino de história para os direitos humanos: se, por um lado, compreendemos que precisamos organizar um currículo ou mesmo uma aula de história que dê conta dos temas desestruturantes da vida dos jovens e da sociedade brasileira nos tempos atuais - que lhes permita compreender o que é o presente e como se orientar nele, construir uma identidade, criar referenciais -, por outro lado, é necessário para a aprendizagem histórica outro salto, que é pensar a diferença na forma da alteridade. Ou seja, "aprendo sobre mim mesmo na relação com o outro, mas, sobretudo, aprendo com o outro a experiência que nunca tive", e é isso o que permite a movimentação no tempo em direção ao futuro para novas experiências.

Com base nessa dupla preocupação, que nos parece estar resumida no campo dos direitos humanos e da aprendizagem histórica na maneira da abordagem das questões sensíveis, procuramos apresentar duas questões interiores a essa dupla preocupação. A primeira consiste em supor que os temas sensíveis indicam outra maneira de construir a temporalidade. Se pensamos um tema sensível ancorado na ideia de que o passado é exterior ao presente, não estamos colocando elementos do campo do sensível para discutir o problema.. Em nossa concepção, um tema sensível vive do paradoxo temporal: o passado convive com o presente; um passado que não passa; um presente que não deixa de ser passado. Um tema sensível não pode ser analisado do ponto de vista cronológico, evolucionista, progressivista, como pensaram os iluministas ou como supõe o eurocentrismo. Para refletir sobre o nazismo é preciso se dar conta de que ele não é algo do passado, que deve ser estudado com distanciamento, do ponto de vista metodológico, que nos coloque numa situação de leitores de algo que nos é exteriorizado. O nazismo é algo que nos indica um paradoxo temporal: ele é, ao mesmo tempo, passado e presente. Os seus efeitos se estendem no presente e, infelizmente, se estenderão, ainda, ao futuro. O racismo, decorrente de escravidão de pessoas negras no Brasil, não é algo que passou: é algo que não passa, não cessa de multiplicar os seus efeitos. Temos aí o paradoxo temporal: ninguém poderá, simplesmente, ensinar a cronologia da escravidão sem pensar que a escravidão não é outra coisa senão o elemento ao qual está ligado o processo de colonialidade e estão ligados os processos de racismo e discriminação que existem em nossa sociedade. 
Faz toda a diferença dar-se conta de que quando penso um tema sensível, tenho que me abrir; tenho que estar em abertura; tenho que estar despersonalizado de todas as determinações que o conhecimento europeu, desde Descartes, tem instituído para a nossa sociedade. Significa que abandonar tanto o racionalismo quanto o empirismo; e, sobretudo, abandonar a ideia de que a cronologia é da própria natureza do tempo e que o pensamento histórico precisa estar sempre a ela submetido. O mais importante que a história nos ensina é que não há nada que possa ser universal; nada que possa se colocar como uma narrativa que abranja todas as outras narrativas. Logo, o tempo cronológico não é outra coisa senão uma criação - e uma criação perversa; tributária de uma espécie de colonialidade do tempo (Quijano, 2005), ${ }^{2}$ de tal modo que a nossa experiência temporal e as nossas relações com o passado, tem sido construídas a partir da colonialidade. Desse modo, a história nos informa exatamente que não há uma representação essencial do tempo, não há uma narrativa universal, não há uma narrativa universal, não há uma única forma de pensar o tempo. A experiência temporal do povo Guarani é absolutamente incomensurável se partirmos dessa temporalidade europeia e eurocentrada.

A segunda questão que nos auxilia a pensar os temas sensíveis é "aprendizagem e experiência”. Estamos propondo que a aprendizagem de um tema sensível só pode ter sentido se for uma aprendizagem da experiência (Bondía, 2002). Quando aprendemos alguma coisa, do ponto de vista da filosofia anterior a Descartes, nos transformarmos com aquilo que aprendemos (Foucault, 2004). A aprendizagem não é vista como um mero acúmulo de qualquer coisa, nem de conceitos, nem de informações. A aprendizagem implica uma transformação subjetiva. A abordagem do genocídio indígena no Brasil pode permitir apenas dizer que ele existiu e discutir as causas desses processos, dar-lhes datas, informações, fazer levantamentos de documentos e assim por diante. Se fizermos apenas isso estaremos abordando um passado frio e disciplinado, exterior, e que é tornado objeto, fato, apartado do sujeito que conhece (White, 2014).

Até Descartes não havia distinção entre aprendizagem e espiritualidade, entre aprender e transformar-se como sujeito. Descartes inaugurou, na filosofia, essa ideia de que o sujeito do conhecimento é tão racional que está absolutamente imune às questões da vida e da experiência: conhecer é algo que permite acumular conceitos e informações. Preferimos seguir a linha da forte 
crítica elaborada por Nietzsche e Marx, no século XIX, e pensar que a aprendizagem implica transformação de si. O que se precisa pensar é justamente a ideia de que aprender sobre o genocídio indígena no Brasil não pode ser algo que o professor simplesmente exponha em aula, como "matéria dada”. Há que se ter acontecimento nessa aula: que alguém chore, que alguém se espante, que alguém ache um absurdo, que alguém diga "professor, o senhor não tem o direito de nos mostrar isso que está nos mostrando! O senhor não tem o direito, é muito forte, é muito pesado!”. Uma aula de história provoca sensações, muito mais que simplesmente ensina causas, efeitos e consequências. A questão que se coloca é que uma aula de história provoca sensações.

$\mathrm{Na}$ percepção que temos da história disciplinar, profissional e, por que não dizer, eurocêntrica, a análise de um fato, a compreensão e a explicação desse fato, é um modo de enclausurá-lo, analisá-lo, compreendê-lo e explicá-lo num passado distante. Essa distância é medida não apenas pelo que de estranho o tempo do fato tem em relação ao presente, mas pela enorme distância entre o objeto e o sujeito do conhecimento. Não se trata de um estranhamento, mas de uma distância epistemológica. A construção da narrativa envolve duas entidades opostas, distantes e apartadas: passado/fato/objeto e presente/sujeito. Esse passado recortado é frio e disciplinado, é tratado como um bibelô pronto a ser objetificado e individualizado pelo discurso. Dessa relação de absoluta exterioridade entre passado, objeto, presente e sujeito não se extrai nada de vida, nada que permita expandir a vida; e expandir a vida é exceder os limites do presente. Essa forma de conhecer o passado tem sido, por muitos anos, comum às salas de aula de história e aos livros didáticos. De outro modo, o passado é vivo, pois não apenas ele insiste no presente, na forma de questões abertas e sensíveis, como também insiste como acontecimento que provoca aprendizagens novas. Desse diagrama que construímos podemos visualizar duas urgências ao ensino de história: as questões sensíveis e a diferença. Diante dessas duas questões - em verdade uma dupla preocupação - situam-se dois elementos da aprendizagem histórica: o paradoxo temporal que pensa presente e passado de uma só vez, e uma aprendizagem da experiência que deixa de apartar sensibilidade e inteligência, corpo e alma, conhecimento e ética.

Dessa forma, temos um passado vivo que se prende ao presente como residualidade ou como remanescência, constituindo o ser do paradoxo temporal. As aulas de história se põem a tomar como conteúdo de ensino e 
aprendizagem as residualidades do passado que não passam, que se estendem ao presente e que habitam a memória, constituindo experiências. A seguir queremos pensar diversas dessas residualidades e remanescências, ou seja, sobrevivências do passado que se instalam na história e na memória e que insistem e nos fazem ver as experiências como virtualidade atuais.

A teoria das residualidades é um roubo que fazemos dos estudos medievais, que se propõe a pensar as permanências e as insistências de elementos do pensamento medieval na atualidade. Como afirma Pontes (Informação Verbal): "Quando falo de resíduo, digo remanescência; se pronuncio resíduo, refiro-me a sobrevivência ... resíduo é aquilo que remanesce de uma época para outra e tem a força de criar de novo toda uma obra, toda uma cultura. $\mathrm{O}$ resíduo é dotado de extremo vigor. Não se confunde com o antigo". ${ }^{3}$ Fizemos uma livre apropriação do conceito para pensar a residualidade como a materialidade do paradoxo temporal. O passado insiste, mas na qualidade de passado, contínuo fluxo que passa, nunca é o mesmo de um momento para o outro. Desse modo, sobrevivem resíduos que se atualizam no presente, guardando em torno de si uma virtualidade que a prende ao passado. Remanescer, nesse sentido, é fazer subsistir o passado no presente. Se os estudos medievais se debruçam sobre elementos da mentalidade medieval (Macedo, 2011), ${ }^{4}$ da literatura e das práticas sociais, e buscam seu modo de ser no presente, o que procuramos são passados residuais que insistem em se manter vivos pela sua própria vitalidade, uma vez que seu caráter de abertura e de infinitude os torna ao mesmo tempo passado e presente.

A preferência pela teoria das residualidades e das remanescências, e não pela ideia de permanência, diz respeito ao fato de que a noção de permanência parece se relacionar com algo fixo, inalterável, que permaneceu, mas queremos, ao contrário, pensar nas diversas apropriações que historicamente se deram com esses passados que insistem no presente.

\section{O ENSINO DOS PASSAdos VIVOS EM ARTICULAÇÃO COM A EDUCAÇÃO EM TEMAS SENSÍVEIS}

Um passado vivo em sala de aula constitui-se dos dois elementos já demoradamente descritos neste artigo: a noção de que um passado vivo continua a fluir ao mesmo tempo que o presente, e a ideia de que sua aprendizagem se 
dá na forma de uma experiência. O que descreveremos a seguir são acontecimentos de salas de aula da escola básica nos quais se pode ver a passagem de um passado vivo que provocou experiências nos estudantes, permitindo uma aprendizagem sobre e com os direitos humanos.

\subsection{Raça: o passado entra estridente pela janela}

Tarde escaldante em Porto Alegre, o pouco vento que circula traz ar de tempestade e chuva que se avizinham. Escola de ensino fundamental, Zona Leste de Porto Alegre, periferia urbana, não muito distante da região do sambódromo, já final do ano letivo. Sentado no fundo da sala, observo o estagiário. Nada está andando muito bem por aqui. Barulho de uma obra na rua logo em frente à escola. Gritaria excessiva de crianças no pátio. Esta turma tem aulas em um prédio ainda de madeira. Tudo range no chão quando alguém caminha ou simplesmente se mexe na cadeira. Há uma dispersão geral no ar. Eu mesmo estou suando e entediado. Aula muito tradicional sobre escravidão no Brasil. Fatos, algumas gravuras de dois livros grandes de pinturas do Debret, datas, nomes, cidades, relato de situações de opressão no trabalho, de censura na vida religiosa, depoimento dramático da separação de mães e filhos no porto de chegada no Rio de Janeiro, histórias de fuga de negros e perseguição pelos feitores. Muita falação, mas nenhuma conexão à situação da população negra no Brasil contemporâneo. Tudo ficou lá atrás, na colônia brasileira, e parece não afetar a vida de ninguém aqui. O estagiário se preparou, coisas interessantes são ditas por ele, mas são chicotadas no mar, não deixam marca nenhuma na classe de jovens. Na sala, o alunado é predominantemente negro ou pardo, e todos com certeza pobres. O estagiário é um rapaz muito jovem, muito bonito, e loiro. Ninguém faz pergunta nenhuma, todos tentam ficar em silêncio; procedendo assim, querem ajudar o estagiário, nota-se que têm simpatia por ele, mas não conseguem estabelecer um diálogo. Ele se esforça para que os alunos participem, está muito nervoso, e eu tenho uma parcela importante de culpa nisso, pois estou aqui como supervisor do estágio. Me apresentei à classe de alunos dizendo claramente que estava ali para avaliar o trabalho docente do estagiário, não tenho como dizer outra coisa, é essa a minha tarefa. Solicitei a colaboração dos alunos e alunas para o sucesso da aula e sentei no fundo, como sempre, com o bloco de anotações na frente. Sempre que escrevo algo no bloco, percebo que os alunos e alunas olham com curiosidade. Já estou contando os 
minutos para que toque a sineta, embora sabendo que terei de voltar outro dia, pois, com um desempenho assim, não há como me dar por satisfeito com o trabalho do estagiário. A tarde está perdida. Aí acontece algo que muda tudo. Uma sirene estridente de polícia se escuta ao longe, vai crescendo, captura a atenção de todo mundo, logo já vemos a viatura policial da brigada militar passando em frente à escola. Nos damos conta de que são duas viaturas, na realidade. Elas reduzem muito a velocidade, a tal obra do outro lado da rua está cercada por montes de saibro, difícil passar pela frente da escola, penso que mesmo o meu carro deve estar atrapalhando o trânsito, pois deixei meio atravessado entre calçada e rua. As sirenes não permitem que se escute mais nada, todo mundo olha, crianças se levantam das cadeiras. A coisa passa, a situação volta ao que estava antes. E uma aluna afirma - ou pergunta - com voz muito audível: "estão perseguindo um negro, que nem lá, onde o professor estava falando, não é?”. Imediatamente a sala fica inundada de observações feitas por outros alunos, nem consigo anotar tudo, pois são muitas falas ao mesmo tempo, mas se escutam afirmações como: "Quando entro no supermercado X (grande rede em Porto Alegre), sempre o fiscal fica me seguindo". "Na padaria lá na faixa os outros pegam o pão no balcão e vão pagar no caixa. Quando sou eu, eles levam o pão ao caixa, eu pago, e só depois eles me entregam o pão". "A minha mãe e eu fomos no crediário, e ela deixou a bolsa na cadeira, enquanto ia beber água no bebedouro, e quando voltou e pegou a bolsa de novo, o guarda veio perguntar se a bolsa era dela mesmo". "Eu disse pra minha tia que eu nem quero mesmo tênis novo no Natal, porque negrão com tênis novo é roubada na certa, é muita explicação o tempo todo". A agitação sobe de tom quando uma aluna diz em voz bem alta "e tem aquela professora querida que falou um dia que para ser empregada doméstica a gente nem precisava estudar muito, no nosso caso, emprego era mais importante do que estudo". O passado ligado à raça e à escravidão não passou; bastou uma sirene, e ele invadiu a sala. Para meu espanto, o estagiário se anima, bate palmas, pede atenção, parece que o ligaram na corrente de 220 volts. Traça uma linha de caneta vermelha dividindo o quadro branco (a única coisa moderna que há nessa sala) e, enquanto escreve, vai dizendo aos alunos "aqui desse lado, a gente vai fazer uma lista de coisas como eram antes, antigamente, no tempo da escravidão; e aqui desse outro lado, a gente vai escrever como é hoje, todo mundo tem que copiar tudo, e depois a gente vai fazer um debate". Percebo que a tarde foi salva pela sirene da polícia. 
Mais surpreso fico quando os alunos listam os elementos "de antigamente" com precisão, ou seja, eles haviam escutado e guardado na memória, talvez apenas não soubessem o que fazer com aquilo. Quando a lista "das coisas de hoje" começa a ser feita, uma aluna sugere que se faça como em alguns exercícios do livro, ligue a coluna da direita com a da esquerda. Todo mundo ri e concorda, os alunos agora estão também conduzindo a aula, o poder se repartiu entre docente e discentes. A afirmação de antigamente, "trabalhavam e não ganhavam salário", fica ligada por uma seta com a afirmação de hoje, "trabalham e ganham o salário mais baixo do mercado". Fazem-se conexões ligadas a local de moradia, religião, maus tratos, preconceito. Verdade seja dita, tudo é feito de modo um tanto aligeirado, mas há agora um vigor na sala, um envolvimento, que contrasta nitidamente com o momento anterior. E assim a aula segue, até que a sineta da troca de períodos interrompe tudo e os alunos correm para fora. Alguém falou que a ventania da chuva já dá para ver ao longe, o desejo de qualquer pessoa sensata numa tarde dessas é que a chuva comece logo. Um menino se aproxima de mim e diz com o ar mais zombeteiro que se possa imaginar: "a gente acha o nosso professor muito massa, mas ele precisa de um empurrão toda hora, é sempre assim, mas ele é mais legal que a nossa professora. Ela, nem adianta empurrar mais, ela não anda". O menino nem espera eu comentar alguma coisa, sai empurrando os outros meninos a sua frente, aos gritos de "empurra gente, empurra gente".

\subsection{Homofobia como residualidade medieval}

Evidentemente, o termo homofobia não se aplica ao passado medieval. Nem mesmo supor a existência de uma legislação que pudesse tornar crime tal prática. Entretanto, resíduos de uma prática que se ocupou de estabelecer um lugar para o outro em função de sua identidade de gênero ou de suas práticas sexuais parece se desprender das circunstâncias e do contexto da vida dos medievais do Ocidente e inserir-se na atualidade, sob outras roupagens, com outros objetivos, como singularidade que se mede pela sua extensão na atualidade. Desse modo, foi possível, em um estudo que preservou as particularidades de cada período, da Idade Média ocidental e da atualidade da sociedade brasileira, pensar a questão dos direitos, da tolerância, das diferenças e de uma questão bem particular do nosso mundo hoje, a homofobia, por meio de um estudo sobre a sodomia e a bruxaria na Idade Média. A porta de entrada, o 
disparador a partir de onde foi possível pensar o presente por uma residualidade medieval entre nós, foram as condenações das práticas sodomitas pela Inquisição medieval, elemento intimamente ligado à misoginia medieval, resíduo igualmente importante nos tempos atuais. ${ }^{5}$ Trata-se de uma questão sensível em todos os seus contornos, historicizada na forma da residualidade e a partir de um disparador que procura não aproximar períodos históricos, mas perceber práticas que se alongam no tempo fazendo passado.

\subsection{O Nazismo como atualidade}

Estudar o nazismo como um passado que não cessa de insistir no presente, tem implicações éticas e políticas, pois seu estudo permite aprender e pensar novas experiências de vida sem o nazismo e suas mazelas. Uma atividade escolar perguntou aos alunos, em primeiro lugar, quando o Nazismo existiu, e todos foram rápidos em afirmar que foi no século XX, na época da Segunda Guerra Mundial. O exercício implicava provocados os alunos com perguntas sobre se existe hoje, no século XXI, intolerância, racismo, condenação do outro em função de sua singularidade, enfim; e todas as respostas eram que sim, tudo isso existia. Foi nesse momento que os estudantes puderam perceber que o Nazismo e tudo do que ele é constituído ainda existe, aliás, teria existido antes dele. Aos alunos foi proposto discutir como seria o mundo hoje se o Nazismo não tivesse existido. O que mais importou foi que os alunos passaram a ver o nazifascismo como algo que não passou, que reside como memória e como prática (foram exemplificadas várias dessas práticas) em nossa sociedade. Para finalizar a atividade, foi colocada uma pergunta no quadro: "E se o Nazismo e o que o constitui nunca tivessem existido, como seria o nosso mundo?". As respostas foram variadas. Mas o importante é que a pergunta moveu a aula de história para o campo da ética, da compreensão do que somos e do que queremos ser neste mundo e, além disso, permitiu aos alunos visualizarem alternativas, pensar alternativas que não aconteceram e que poderiam ainda acontecer num futuro imprevisível.

Em sintonia com a exposição teórica e a narrativa de situações escolares expostas, concluímos este texto propondo uma espécie de conceituação, que reconhecemos ainda em construção, do que entendemos por educação em temas sensíveis no ensino de história, em estreita articulação com a noção de ensino dos passados vivos. Não se trata propriamente de uma conceituação, 
mas de uma curta listagem de elementos centrais para pensar essa modalidade de ensino. O primeiro deles é assumir na aula de história que o passado nunca passou exatamente, ele está vivo e atuante no presente de alunos e professores, e isso se manifesta de modos muito diversos. O conceito de residualidades é peça-chave para lidar com esse "passado que nunca passa", e que, portanto, ajuda a produzir quem somos no presente. O segundo elemento é pensar que os temas sensíveis não são dados a priori, não há como construir uma listagem de temas sensíveis que exista para sempre e propor, então, atividades para cada um, à moda de uma "lista de conteúdos e suas atividades". A produção dos temas sensíveis é fruto de uma relação entre passado e presente, entre o programa de história e as marcas das culturas juvenis e do contemporâneo. Exige, então, sensibilidade da parte do professor, e só confirma o ditado de que o bom professor de história é alguém que mergulha no passado com os pés bem firmes no presente, e esse presente inclui compreender a atualidade dos alunos. $\mathrm{O}$ terceiro elemento é assumir que os temas sensíveis são atravessados por fortes divergências de opinião e aceitar isso como constitutivo da aula de história, que busca mais debate do que propriamente a produção de consensos ou verdades acabadas do tipo "o que realmente aconteceu na história". A potência da aula e a produtividade do ensino de história se revelam no vigor dos debates, no clima de liberdade de expressão, no respeito aos direitos humanos e na aposta de que todos saiam transformados em suas identidades (Mouffe, 2003).

Em sintonia com isso, o quarto elemento diz respeito a pensar a aula de história animada pela noção de modus vivendi, valorizando nela um elemento fundamental de sua história, que é a disposição para a capacidade de construir acordos entre indivíduos e grupos cujas opiniões diferem, disposição que entende o espaço público como local de negociação intensa entre projetos diferentes e legítimos (Seffner, 2015). Tal dinâmica vai muito além do que em geral se afirma sobre a inclusão e a diversidade. Não se trata apenas de "reconhecer" que o outro é diferente, e "aceitar" que ele seja incluído. Trata-se de realizar um movimento de forte alcance pedagógico, de colocar-se na posição do outro e aceitar modificações na sua própria posição tendo em vista a existência do outro. As narrativas da história deslocam nossas narrativas pessoais, e esse é o valor de seu estudo, é para isso que se estuda história, e não para simples conhecimento de registros do passado (Albuquerque Júnior, 2016). Um quinto e último elemento é pensar toda a aula de história como também inserida no 
campo da educação em direitos humanos, tal como apresentamos na introdução deste artigo, e devidamente amparada em legislação educacional brasileira e em consensos internacionais. Para os tempos atuais, essa é a aula de história que nos parece fazer diferença.

\section{REFERÊNCIAS}

ALBUQUERQUE JÚNIOR, Durval M. de. Regimes de historicidade: como se alimentar de narrativas temporais através do ensino de história. In: GABRIEL, Carmen Teresa; MONTEIRO, Ana Maria; MARTINS, Marcus Leonardo B. (Org.) Narrativas do Rio de Janeiro nas aulas de história. Rio de Janeiro: Mauad, 2016. p.21-42.

BLOCH, Howard R. Misoginia medieval e a invenção do amor romântico ocidental. Trad. Cláudia Moraes. Rio de Janeiro: Ed. 34, 1995.

BONDÍA, Jorge Larrosa. Notas sobre a experiência e o saber de experiência. Revista Brasileira da Educação, Rio de Janeiro, n.19, 2002.

BRASIL. Comitê Nacional de Educação em Direitos Humanos. Plano Nacional de Educação em Direitos Humanos. Brasília: Secretaria Especial dos Direitos Humanos, 2006. Disponível em: https://goo.gl/A51Fku; acesso em: 25 dez. 2017.

BRASIL. Secretaria de Direitos Humanos da Presidência da República. Educação em direitos humanos: diretrizes nacionais. Brasília: Coordenação Geral de Educação em SDH/PR, 2013. Disponível em: https://goo.gl/UG8FNP; acesso em: 25 dez. 2017.

FOUCAULT, Michel. A hermenêutica do sujeito. São Paulo: Martins Fontes, 2004.

GIACOMONI, Marcello P.; PEREIRA, Nilton M. (Org.) Jogos e ensino de história. Porto Alegre: Evangraf, 2013.

GIL, Carmen Z. de V.; SEFFNER, Fernando. Dois monólogos não fazem um diálogo: jovens e ensino médio. Educação e Realidade, Porto Alegre, v.41, n.1, p.175-192, 2016.

GIL, Carmen Z. de V. et al. Ensinar, pesquisar, ensinar: a experiência dos Mestrados Profissionais. PerCursos, Florianópolis, v.18, p.8-32, 2017.

GOMES, Ana Valeska A. Gestão democrática no Plano Nacional de Educação. In: GOMES, Ana Valeska A.; BRITTO, Tatiana F. Plano Nacional de Educação: construção e perspectivas. Brasília: Câmara dos Deputados, 2015. Disponível em: https://goo.gl/qcrXQA; acesso em: 25 dez. 2017.

JENKINS, Keith. A História repensada. Trad. Mario Vilela. Rev. técnica de Margareth Rago. São Paulo: Contexto, 2001. 
MACEDO, José Rivair. Sobre a Idade Média Residual no Brasil. In: . (Org.) A Idade Média portuguesa e o Brasil: reminiscências, transformações, ressignificações. Porto Alegre: Vidráguas, 2011. p.9-20.

MEINERZ, Carla Beatriz et al. (Org.) Caderno pedagógico de história Pibid/UFRGS: saberes e práticas de professores de História em formação. Porto Alegre: Ed. UFRGS, 2013.

MOUFFE, Chantal. Democracia, cidadania e a questão do pluralismo. Política \& Sociedade, Florianópolis, n.3, p.11-26, out. 2003. Disponível em: https://goo.gl/sttGGY; acesso em: 28 dez. 2017.

ORGANIZAÇÃO DAS NAÇÕES UNIDAS (ONU). Declaração Universal dos Direitos Humanos. Rio de Janeiro: Unic Rio, 2009. Disponível em: https://goo.gl/uKU03U; acesso em: 25 dez. 2017.

. Plano de ação: Programa Mundial para Educação em Direitos Humanos primeira etapa. Genebra: Unesco; EACDH, 2006. Disponível em: https://goo.gl/ UgKH1F; acesso em: 25 dez. 2017.

PEREIRA, Nilton M. Ensino de história e resistência: notas sobre uma história menor. In: PAIM, Elison Antônio (Org.) Patrimônio cultural e escola. Florianópolis: Ed. UFSC, 2017b. p.227-246.

. A invenção do medievo: narrativas sobre a Idade Média nos livros didáticos de história. In: ROCHA, Helenice; REZNIK, Luís; MAGALHÃES, Marcelo de S. (Org.) Livros didáticos de história: entre políticas e narrativas. Rio de Janeiro: Ed. FGV, 2017a. p.169-184.

PEREIRA, Nilton M.; GITZ, Ilton. Ensinando sobre o Holocausto na escola: informações e propostas para professores dos ensinos fundamental e médio. Porto Alegre: Penso, 2013.

PEREIRA, Nilton M.; RODRIGUES, Mara Cristina de M. Ensino de história e passado prático: notas sobre a BNCC. In: HALFERD JR., Carlos R.; VALÉRIO, Mairon E. (Org.) Ensino de história e currículo. Jundiaí: Paco, 2017. p.27-46.

QUIJANO, Aníbal. A colonialidade do saber: eurocentrismo e ciências sociais. Perspectivas latino-americanas. Buenos Aires: Clacso, 2005.

SEFFNER, Fernando. Escola pública e função docente: pluralismo democrático, história e liberdade de ensinar. In: MACHADO, André Roberto; TOLEDO, Maria Rita de A. (Org.) Golpes na História e na escola: o Brasil e a América Latina nos séculos XX e XXI. São Paulo: Cortez, 2017a. p.199-216.

. Escola pública e professor como adulto de referência: indispensáveis em qualquer projeto de nação. Educação Unisinos, São Leopoldo, v.20, n.1, p.48-57, 2016. 
SEFFNER, Fernando. Leitura e escrita na história. In: NEVES, Iara Conceição B. et al. (Org.) Ler e escrever: compromisso de todas as áreas. Porto Alegre: Ed. UFRGS, 1998. p.105-118.

Modus vivendi, liberdade religiosa e liberdade sexual: o que a escola tem a ver com isso? In: NARDI, Henrique C.; MACHADO, Paula S.; SILVEIRA, Raquel da S. (Org.) Diversidade sexual e relações de gênero nas políticas públicas: o que a laicidade tem a ver com isso? Porto Alegre: Deriva; Abrapso, 2015. p.81-104.

Ocupar é viver a escola. In: CATTANI, Antonio David (Org.) Escolas ocupadas. Porto Alegre: CirKula, 2017b. p.13-40.

SEFFNER, Fernando et al. Conexões entre escola e universidade: o PIBID e as estratégias de residência docente. Revista História Hoje, São Paulo: Anpuh, v.4, n.8, p.366-388, 2016.

SEFFNER, Fernando; PEREIRA, Nilton M. História, leitura e escrita no ensino médio. In: PEREIRA, Nilton M. et al. (Org.) Ler e escrever: compromisso no Ensino Médio. Porto Alegre: Ed. UFRGS, 2008. p.165-178.

SEFFNER, Fernando; PICCHETTI, Yara de P. A quem tudo quer saber, nada se the diz: uma educação sem gênero e sem sexualidade é desejável? Reflexão e Ação, Santa Cruz do Sul, RS, v.24, n.1, p.61-81, 2016.

WHITE, Hayden. Meta-história: a imaginação histórica do século XIX. Trad. José Laurênio de Melo. São Paulo: Edusp, 1995. The Practical Past. Evanston, IL: Northwestern University Press, 2014.

\section{NOTAS}

${ }^{1}$ Tal estrutura pode ser conhecida no sítio web mantido pela Rede Direitos Humanos, organização não governamental que atua em estreita sintonia com as políticas públicas da área. Disponível em: https://goo.gl/Yr17UJ; acesso em: 25 dez. 2017.

${ }^{2}$ QUIJANO (2005) elaborou a ideia de colonialidade do poder, com respeito aos processos de constituição histórica das relações de desigualdade baseada na raça, estabelecidas pelos europeus desde o processo de colonialismo.

${ }^{3}$ Entrevista sobre a Teoria da Residualidade, com Roberto Pontes, concedida a Rubenita Moreira (5 e 14 jun. 2006), e lida na Jornada da Residualidade, em 13 de julho de 2006 na Universidade Federal do Ceará (UFC). O professor Pontes faz parte do Grupo de Estudos de Residualidade Literária e Cultural (Gerlic), que atua desde 1991 no Curso de Letras/ Departamento de Literatura da UFC.

4 "Por 'residualidades medievais' ou 'reminiscências medievais' devem-se entender justamente as formas de apropriação dos vestígios do que um dia pertenceu ao medievo, alterados e/ou transformados no decurso do tempo. Nesta categoria encontram-se, por exemplo, 
as festas, os costumes populares, as tradições orais de cunho folclórico que remontam aos séculos anteriores ao XV e que preservam algo ainda do momento em que foram criados, mesmo tendo sofrido acréscimos, adaptações, alterações. Festas como a de Corpus Christi, as Folias de Reis e a Festa do Divino Espírito Santo, o Natal, e mesmo o Carnaval, foram um dia 'medievais' e persistem, mas não da mesma forma, nem desempenhando os mesmos papéis na Europa ou em outras partes do mundo para onde foram levadas" (MACEDO, 2011, p.13).

${ }^{5}$ Sobre a misoginia medieval, ver BLOCH (1995).

Artigo recebido em 3 de janeiro de 2018. Aprovado em 27 de agosto de 2018. 